\title{
Active lgG4-related disease with bone marrow involvement: a report of 2 cases and case-based review
}

Shiyi Liu ${ }^{1,2,3}$, Hui Wang ${ }^{4}$ and Tao Su S, $^{\text {* }}$ (i)

\begin{abstract}
IgG4-related disease (IgG4-RD) is a systemic fibro-inflammatory disease, histopathologically characterized by dense lymphoplasmacytic infiltration rich in IgG4-positive plasma cells in affected organs. Classic hematologic presentations including lymphadenopathy, eosinophilia and polyclonal hypergammaglobulinemia are common, whereas bone marrow involvement of IgG4-RD is rarely reported. Here we present two patients of multi-organ IgG4-RD with bone marrow involvement, one on bone marrow biopsy, and the other on PET/CT. Presentations of other organ involvement included biopsy-proven IgG4-related tubulointerstitial nephritis, lymphadenopathies, submaxillary glands, arteritis, asthma, dysosmia, and constitutional symptoms. Bone marrow involvement was initially suspected due to leukopenia, anemia and thrombocytopenia in case\#1, and was finally confirmed by histological evidence of significant IgG4-positive plasma cells infiltration in bone marrow. In case\#2, we incidentally observed high uptakes of multi-bone marrow on ${ }^{18} \mathrm{~F}$-FDG-PET/CT, with the maximum SUV value similar to that of the kidneys, submaxillary glands and hilar, mediastinal lymph nodes by ${ }^{18} \mathrm{~F}-\mathrm{FDG}-\mathrm{PET} / \mathrm{CT}$. Symptoms and all the hematologic presentation improved rapidly in both patients after steroids initiation. These two cases illustrate the rare bone marrow involvement in active lgG4-RD accompanied by other hematologic syndromes. The significance of disease pathogenesis is worthy of further study.
\end{abstract}

Keywords: IgG4-related disease, Bone marrow, Hematologic, Leukopenia, Thrombocytopenia, ${ }^{18} \mathrm{~F}-\mathrm{FDG}-\mathrm{PET} / \mathrm{CT}$

\section{Introduction}

IgG4-related disease (IgG4-RD) is a fibro-inflammatory condition recognized for decades, characterized by multi-organ enlargement with histopathological dense lymphoplasmacytic infiltration rich in IgG4-positive plasma cells, storiform fibrosis and obliterative phlebitis. IgG4-RD was first reported in patients with autoimmune pancreatitis (AIP) and it was gradually recognized as a systemic immune disease over the following years $[1,2]$. Usually, most patients with IgG4-RD present with polyclonal hypergammaglobulinemia, which is typically

*Correspondence: tao.su@bjmu.edu.cn

${ }^{1}$ Renal Division, Department of Medicine, Peking University First Hospital, Beijing, China

Full list of author information is available at the end of the article caused by elevation of serum IgG4 [3]. Additionally, elevated serum IgG4 is much more common in Asian patients than patients of European descent $[4,5]$. Nearly all the tissues can be involved, especially the pancreas, salivary glands, biliary duct, liver and kidneys. Hematologic manifestations of IgG4-RD have also been recognized, such as lymphadenopathy [6]. But case reports of bone marrow (BM) involvement were rare.

Here, we present two patients of IgG4-RD with bone marrow involvement. One patient had significant IgG4-positive plasma cells infiltration in bone marrow aspiration and biopsy samples. In the other patient, hematologic involvement was detected by 18 fluorodeoxyglucose positron emission tomography $\left({ }^{18} \mathrm{~F}-\mathrm{FDG}-\mathrm{PET} /\right.$ $\mathrm{CT})$, showing high uptakes in multi-bone marrow. These 
reports suggest the possibility of hematologic pathogenesis of IgG4-RD.

\section{Materials and methods Case presentation}

Case 1 was a 68-year-old Chinese male who complained of upper abdominal pain with aggravation of renal function. He had a 2-year history of repeated upper abdominal pain suspected as "ileus" and suffered frequent attacks during the last 9 months. The patient developed acute kidney injury initially as serum creatinine (Scr) was insidiously elevated from 270 to a peak of $410 \mu \mathrm{mol} / \mathrm{L}$, and went back to normal range after supportive treatment. However, symptoms relapsed 2 weeks before his hospital admission to Peking University First Hospital. The abdominal enhanced-CT scan revealed swelling kidneys with renal parenchyma patchy filling defects, and dilated small bowel loops. Thickening of the abdominal aorta, superior mesenteric and splenic artery walls could also be recognized (Fig. 1).

Laboratory testing details on admission are shown in Table 1. The patient had mild leukopenia, anemia and thrombocytopenia. The Scr was $326 \mu \mathrm{mol} / \mathrm{L}$ in the presence of mild proteinuria. The serum protein electrophoresis showed polyclonal hypergammaglobulinemia (IgG $29.56 \mathrm{~g} / \mathrm{L}$, IgG4 $11.7 \mathrm{~g} / \mathrm{L}$ ), and no monoclonal band was detected. ${ }^{18}$ F-FDG-PET/CT scan showed high uptakes in bilateral submaxillary glands, kidneys, hilar and mediastinal lymph nodes (Table 1, Fig. 2). In contrast, abdominal aorta, superior mesenteric, splenic arteries and bone marrow showed no hypermetabolic lesions.

The patient underwent a right kidney biopsy. Renal pathology disclosed ischemic sclerotic glomeruli (19/28, $67.9 \%$ with mild mesangial proliferation and typical IgG4-related tubulointerstitial nephritis. The ratio of IgG4/IgG was $65 \%$ (Fig. 3) in immunohistologic staining. Renal fibrosis was remarkable and "storiform" fibrosis existed in the local area. The formation of an ectopic germinal center was found. He also had a posterior superior iliac spine bone marrow examination because of unexplained leukopenia and thrombocytopenia. Analysis of bone marrow could exclude hematologic malignancies. Bone marrow proliferation was active. Granulocyte lines accounted for $65.5 \%$, with the ratio of granulocyte to erythroid at 2.5:1. Five megakaryocytes could be seen in the whole BM smear $(2.0 \times 0.5 \mathrm{~cm})$, and no plasma cell was observed in BM aspirate. In BM biopsy, we found CD138 and IgG-positive plasma cells were scattered in the BM interstitium with some eosinophils, and 50\% of these IgG-positive plasma cells were also positive for IgG4 (IgG 40/HP, IgG4 20/HP). The plasma cells presented weak positives for kappa and lambda light chains (Fig. 3). Together, the diagnosis of IgG4-RD was confirmed with six sites involved and constitutional symptoms. The patient was prescribed prednisolone $40 \mathrm{mg} /$ day. Symptoms were relieved soon after prednisolone initiation. The peripheral blood cell count returned to normal. Scr declined to $240 \mu \mathrm{mol} / \mathrm{L}$ one month after hospital discharge and remained at $180 \mu \mathrm{mol} / \mathrm{L}$ during the subsequent year.

Case 2 was a 38-year-old male referred to the nephrology clinic for investigation of renal insufficiency as his serum creatinine was $146 \mu \mathrm{mol} / \mathrm{L}$. He presented severe fatigue, dysosmia and conspicuous weight loss of 11 pounds during the last 2 months. He had a history of anaphylactic rhinitis and bronchial asthma. On admission, blood pressure was $150 / 90 \mathrm{mmHg}$, physical examination revealed bilateral submandibular gland swelling with left supraclavicular lymphadenopathy, and these were later confirmed by ultrasonography and FDG-PET/CT scan.

Laboratory tests are summarized in Table 1. It showed obvious eosinophilia with normal WBCs and platelet count. There was a remarkable hyperglobulinemia (IgG 64.8 g/L, IgG4 47.2 g/L, IgE 1761 kU/L). No
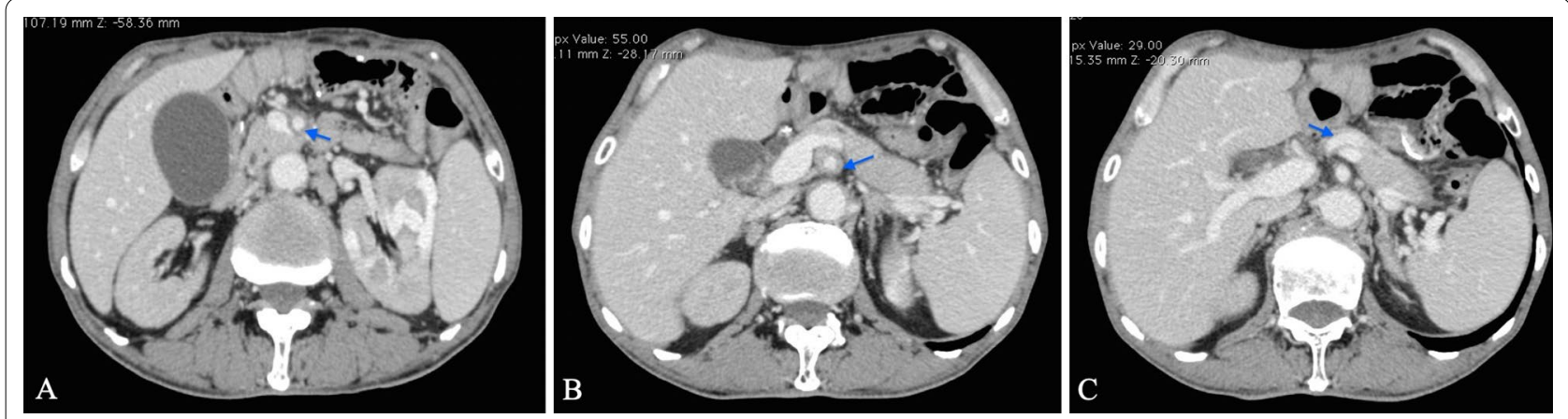

Fig.1 Enhanced computed tomography scan of patient 1: diffuse aortic wall thickening in the superior mesenteric (A, arrow in blue), abdominal aorta (B) and splenic arteries (C) 
Table 1 Clinical, laboratory and radiological findings in two lgG4-RD patients

\begin{tabular}{|c|c|c|}
\hline & Case 1 & Case 2 \\
\hline \multirow[t]{3}{*}{ IgG4-related clinical symptoms } & $A K I, A K D$ on $C K D$ & AKD \\
\hline & Ileus & Asthma, rhinitis \\
\hline & Fatigue & Fatigue, weight loss \\
\hline \multicolumn{3}{|l|}{ IgG4-RD involved organs, identified by } \\
\hline \multirow{4}{*}{$\begin{array}{l}\text { Clinical presentation/enhanced-CT/US (measured by } \\
\text { US, } \mathrm{cm}^{3} \text { ) }\end{array}$} & Kidneys $(13.0 \times 6.3 \times 5.8 / 12.2 \times 5.9 \times 4.5)$ & Kidneys $(13.0 \times 7.5 \times 6.4 / 13.3 \times 6.6 \times 5.7)$ \\
\hline & Submaxillary glands & Submaxillary glands \\
\hline & Abdominal aortitis & - \\
\hline & Superior mesenteric, splenic arteritis & - \\
\hline \multirow[t]{2}{*}{ Pathology } & Kidney (right) & Kidney (right) \\
\hline & Bone marrow & ND \\
\hline \multirow[t]{4}{*}{ FDG-PET/CT (SUV max) } & Kidneys (5.0) & Kidneys (3.7) \\
\hline & Submaxillary glands (3.0) & Submaxillary glands (2.9) \\
\hline & Hilar, mediastinal lymph nodes (4.0) & Hilar, mediastinal lymph node (3.5) \\
\hline & - & Bone marrow (3.6) \\
\hline Number of involved sites & 6 & 6 \\
\hline \multicolumn{3}{|l|}{ Laboratory data } \\
\hline WBC $\left(3.5-9.5 \times 10^{9} / L\right)$ & 3.4 & 4.2 \\
\hline NE (40.0-75.0\%) & 60.8 & 54.8 \\
\hline LY (20.0-50.0\%) & 27.2 & 18.8 \\
\hline EO $(0.4-8.0 \%)$ & 4.0 & 15.0 \\
\hline Platelet count $\left(125-350 \times 10^{9} / \mathrm{L}\right)$ & 110 & 173 \\
\hline Hemoglobin (130-175 g/L) & 108 & 122 \\
\hline Total protein $(65-85 \mathrm{~g} / \mathrm{L})$ & 73.1 & 99.5 \\
\hline Albumin (40-55 g/L) & 34.3 & 36.7 \\
\hline BUN (1.8-7.1 mmol/L) & 17.27 & 7.2 \\
\hline 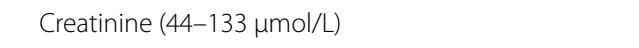 & 326 & 146 \\
\hline Amylase (35-135 IU/L) & 219 & ND \\
\hline C3 $(0.6-1.5 \mathrm{~g} / \mathrm{L})$ & 0.519 & 0.486 \\
\hline C4 (0.12-0.36 g/L) & 0.15 & 0.113 \\
\hline $\operatorname{lgG}(7.23-16.85$ g/L) & 29.56 & 64.77 \\
\hline $\lg G 1(4.90-11.40 \mathrm{~g} / \mathrm{L})$ & 8.35 & 12.60 \\
\hline $\operatorname{lgG} 2(1.69-7.86$ g/L) & 8.01 & 3.57 \\
\hline $\operatorname{lgG3}(0.11-0.86 \mathrm{~g} / \mathrm{L})$ & 1.50 & 1.40 \\
\hline $\operatorname{lgG} 4(0.03-2.01$ g/L) & 11.70 & 47.20 \\
\hline $\lg A(0.69-3.82 \mathrm{~g} / \mathrm{L})$ & 2.33 & 1.01 \\
\hline $\operatorname{lgM}(0.63-2.77 \mathrm{~g} / \mathrm{L})$ & 0.50 & 0.57 \\
\hline $\lg E(<100 \mathrm{kU} / \mathrm{L})$ & ND & 1761 \\
\hline hs-CRP (0.0-3.0 mg/L) & 8.56 & 9.99 \\
\hline $\operatorname{ESR}(0-15 \mathrm{~mm} / \mathrm{h})$ & 52 & 92 \\
\hline Urinary protein (0-0.15 g/day) & 0.53 & 0.41 \\
\hline ANA & $1: 3200$ & $<1: 100$ \\
\hline dsDNA (IU/mL) & 262 & $<1: 10$ \\
\hline Lymphocytes T CD4+ (34.0-70.0\%) & ND & 38.26 \\
\hline Lymphocytes T CD8+ (14.0-41.0\%) & ND & 57.46 \\
\hline
\end{tabular}

$A K I$ acute kidney injury, $A K D$ acute kidney disease; $N D$, no data; US ultrasonography

monoclonal immunoglobulin was detected by immunofixation electrophoresis from serum and urine. ${ }^{18}$ F-FDG-PET/CT showed high uptakes in bilateral submandibular glands, kidneys and bilateral scapula, spine, sternum, ribs, pelvis, and upper femur (Fig. 2), indicating signs of IgG4-relating lesions including bone 


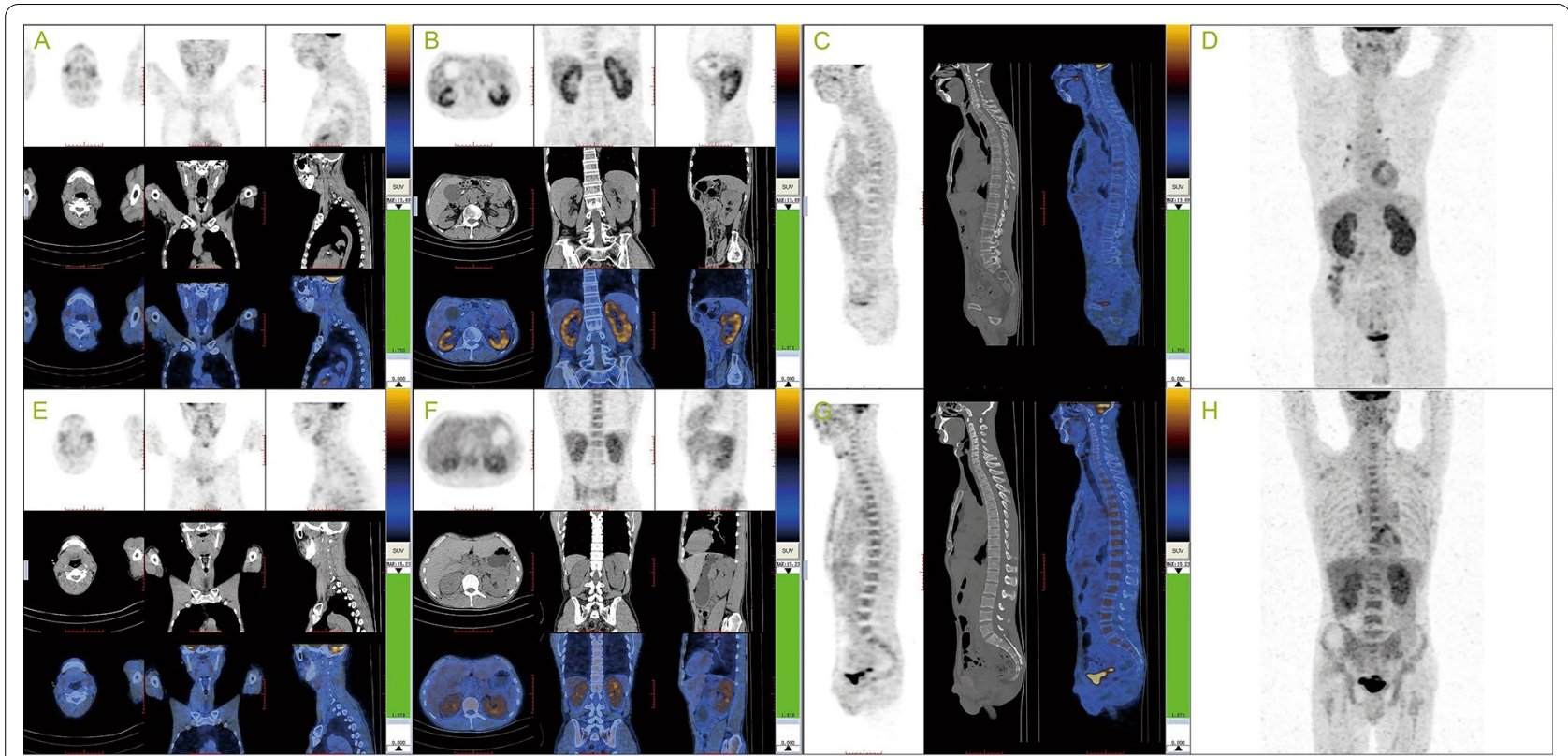

Fig.2 Positron emission tomography-computed tomography scans of the two patients. Patient 1, high uptakes in bilateral submandibular glands (A, SUV ${ }^{\max }$ 3.0), kidneys (B, SUV ${ }^{\max }$ 5.0), hilar and mediastinal lymph nodes on MIP images (D); absence of bone marrow (C). Patient 2, high uptakes in bilateral submandibular glands (E, SUV ${ }^{\max } 2.9$ ), kidneys (F, SUV $\left.{ }^{\max } 3.7\right)$, bone marrow (G, SUV $\left.{ }^{\max } 3.6\right)$, hilar and mediastinal lymph nodes on MIP images $(\mathbf{H})$

marrow. Kidney pathological findings showed that all glomeruli were mildly changed without immune deposits on immunofluorescence. There were massively infiltrated inflammation cells in the renal interstitium including lymphocytes, plasma cells and eosinophils, as well as diffuse interstitial fibrosis accompanied by local storiform fibrosis. IgG4 to IgG-positive plasma cells were $40 \%$ (Fig. 3). A diagnosis of IgG4-related tubulointerstitial nephritis was made.

The patient was initiated on prednisolone combined with plasmapheresis. Four weeks later when he was dismissed from hospital, his IgG4 decreased to $1.49 \mathrm{~g} / \mathrm{L}$ and Scr to $108 \mu \mathrm{mol} / \mathrm{L}$. Two doses of Rituximab $375 \mathrm{mg} / \mathrm{m}^{2}$ with a 4-week interval were infused. The patient currently remained stable for 2 years.

\section{Literature search}

A systematic review of the literature was done of IgG4RD with involvement of bone marrow published before September 2021 on PubMed/MEDLINE. Our search included a combination of keywords such as, "IgG4related disease", "bone marrow", "thrombocytopenia", "leukopenia" and "anemia". Our search was limited to English articles including original articles, review articles and case reports. Reported hematologic presentations which were irrelevant to IgG4-RD or did not contain detailed information were excluded.

\section{Discussion}

IgG4-RD is a systemic disease characterized by largely consistent pathomorphological manifestations across a wide range of organ systems. We call it a pathologically fibro-inflammatory pattern with enlarged organs or tissues. With the increasing number of reports and research in this field, clinicians have gradually become familiar with this syndrome. IgG4-related bone marrow presentation has rarely been mentioned before [7], since fibrosis and obliterative phlebitis is typically not seen, resulting in insensitivity to diagnosis [8]. Kamisawa et al. firstly described histologic feature of IgG4-positive plasma cell infiltration of the BM in two patients with AIP in 2003 [9]. Moreover, in a case report of isolated IgG4-RKD with kappa light chain deposit, BM biopsy revealed around $20 \%$ of plasma cell infiltration without monoclonal paraprotein [8]. As reported in published studies, BM involvement of IgG4-RD usually presented pancytopenia, accompanied by other hematologic manifestations, including lymphadenopathy, eosinophilia and polyclonal hypergammaglobulinemia [6], and was finally confirmed by subsequent $\mathrm{BM}$ pathology. In addition, a case of IgG4-RD primarily presenting as multiple vertebral BM lesions on MR imaging and ${ }^{18} \mathrm{~F}$-FDG-PET/CT [10], was finally identified IgG4-related BM involvement by pathology. A recently published PET/CT research by Schmidkonz et al. [11] declared that lesions with high uptake in ${ }^{18} \mathrm{~F}$-FDG-PET/CT showed dense lymphoplasmacytic 

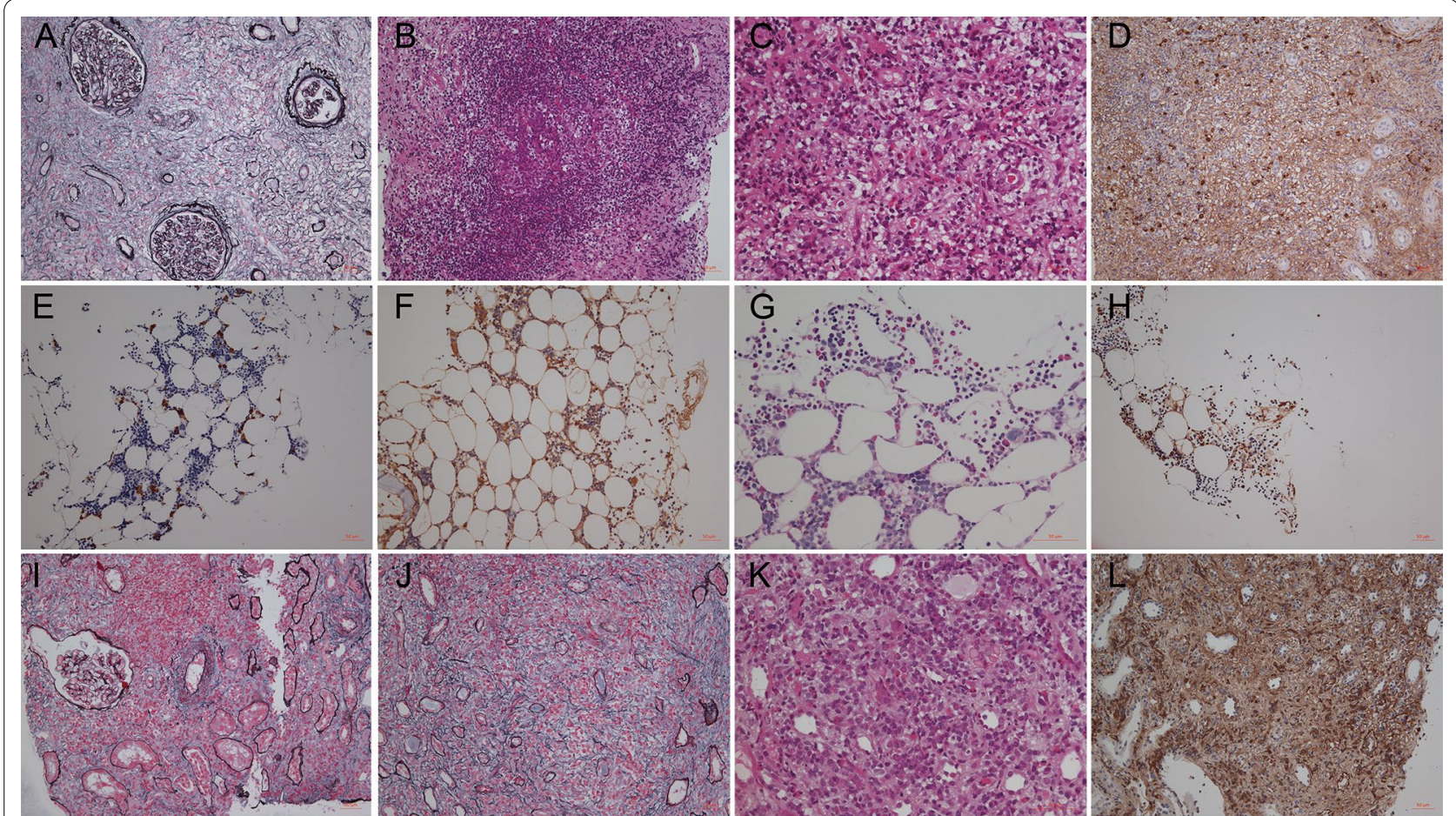

Fig. 3 Histopathological findings of kidneys and the bone marrow. Patient 1, renal fibrosis was remarkable, "storiform" fibrosis existed in the local area (A, H\&E stain, $200 \times$ ). The formation of an ectopic germinal center-like structure was seen in the local interstitium (B, H\&E stain, $200 \times$ ). In local interstitium, diffuse inflammatory cells infiltration was seen in the interstitium, mainly lymphocytes, plasma cells and easily observed eosinophils (C, H\&E stain, $400 \times$ ) on hematoxylin and eosin staining. IgG4-positive plasma cells counted more than 10 cells per high power field on immunohistochemical staining for lgG4 (D, lgG4 stain, $200 \times$ ). The bone marrow proliferation of patient 1 was active, no obvious abnormality was found in granulocyte and lymphocyte lines from BM samples. However, we found CD138 (E, CD138 stain, $200 \times)$ and lgG (F, lgG stain, $200 \times$ ) positive plasma cells were scattered in the bone marrow interstitium with some eosinophils (G, eosinophils stain, $400 \times$ ), and $50 \%$ of these IgG-positive plasma cells were positive for lgG4 (H, lgG4 stain, $200 \times$ ). The plasma cells presented weak positive of both kappa and lambda light chain. Patient 2 had massively infiltrated inflammation cells in the renal interstitium including lymphocytes, plasma cells and eosinophils $(\mathbf{I}, \mathrm{H} \& \mathrm{E}$ stain, $200 \times ; \mathbf{K}$, H\&E stain, $400 \times$ ). The large area of interstitial fibrosis with local typical storiform pattern could be observed on hematoxylin and eosin staining (J, H\&E stain, $200 \times$ ). IgG4-positive plasma cells counted more than 10 cells per high power field on immunohistochemical staining for lgG4 (L, lgG4 stain, $200 \times$ )

infiltration of IgG4 cells in histology; and that fibroblast activation protein imaging could disentangle inflammatory from fibrotic disease activity. In the current study, we reported one patient (\#1) showing IgG4-dominated plasma cells infiltration in BM, with no hypermetabolic lesion found in FDG-PET/CT. For another patient (\#2), we identified elevated FDG uptake lesions involving multi-bone marrow in the context of the active IgG4-RD. Reported cases of definite IgG4-related bone marrow involvement were rare as listed in Table 2. A recent flow cytometric analysis found different immunophenotyping of atypical plasma cells in peripheral blood (accounting for $58.3 \%$, expressing $\mathrm{CD} 19^{\text {low }} / \mathrm{CD} 38^{+} / \mathrm{CD} 138^{\mathrm{dim}} /$ $\mathrm{CD} 56^{-} / \mathrm{CD} 45^{+}$) and in the $\mathrm{BM}$ (accounting for $64.3 \%$, expressing $\mathrm{CD} 19^{\text {low }} / \mathrm{CD} 38^{+} / \mathrm{CD} 138^{+} / \mathrm{CD} 56^{+} / \mathrm{CD} 45^{\text {low }}$ ) [12]. As an adhesion molecule, the difference in CD56 expression might be related to the migration ability to the circulating system. However, the exact explanation was unclear.

Lymphadenopathy is the common presentation in IgG4-RD. Involved lymph nodes typically have $>100$ IgG4 + plasma cells/HPF with an IgG4/IgG ratio $>40 \%$. In addition, some pathologists have noticed ectopic germinal centers formed in IgG4-RD affected tissues and their possible relationship with dense deposits along tubular basement membrane [13,14], as findings showed in our case\#1. Peripheral lymph tissues mainly include lymph nodes and mucosa-associated lymphoid tissue where circulating plasmablasts, an indicator of IgG4-RD disease activity, further differentiate and proliferate to form mature plasma cells and produce antibodies [15]. And tissue-resident antibody-secreting plasma cells are the major interstitial infiltrating inflammation cells. As reported in many clinical studies, serum IgG4 level correlates with lymph node involvement and the number 


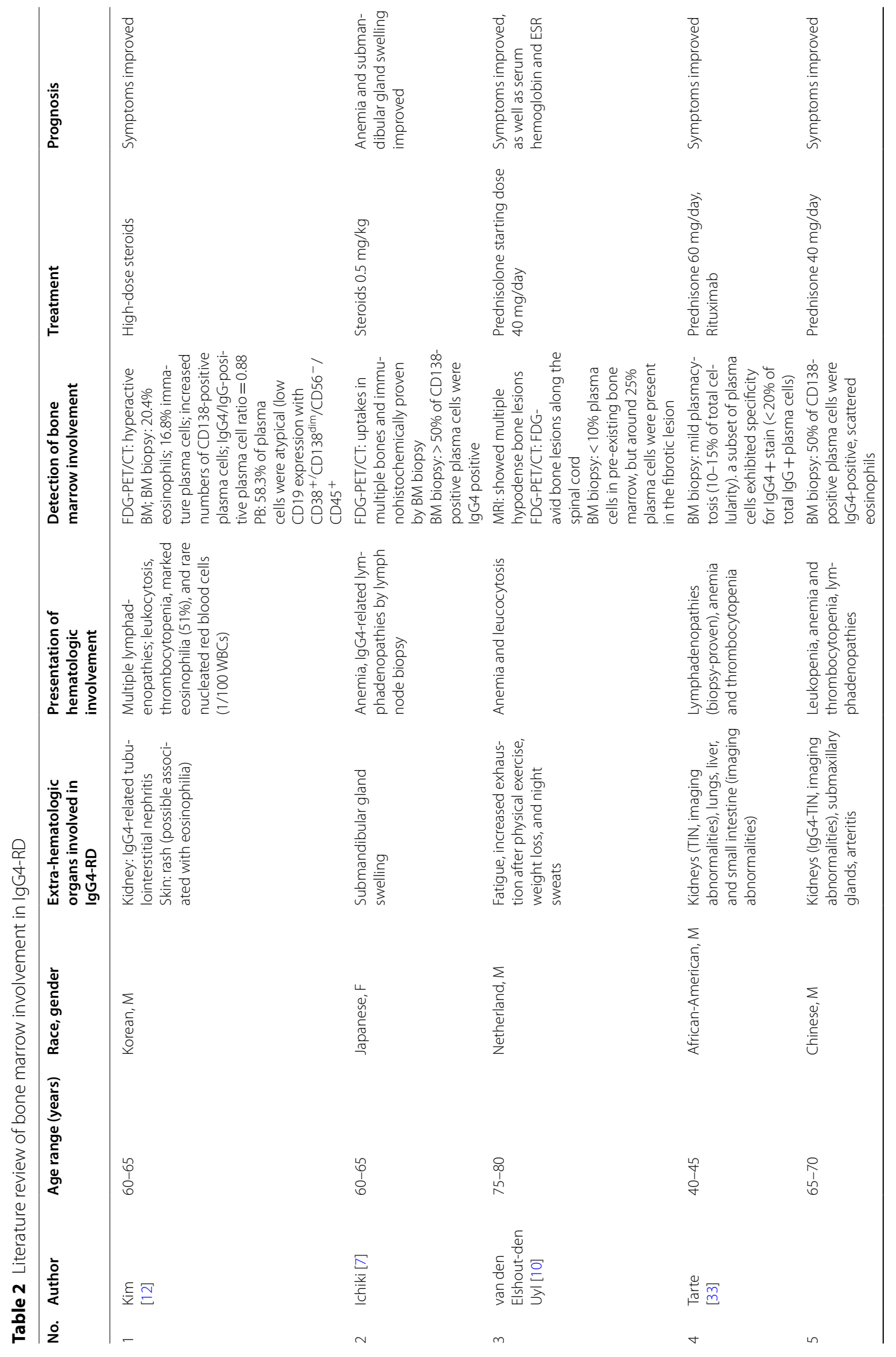




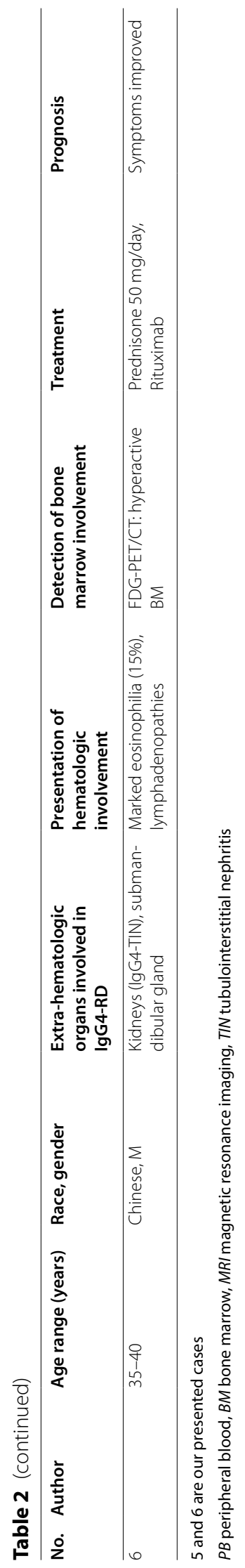


of affected organs. IgG4-RD may also be related to the occurrence of hematologic tumors. The elevated level of plasmablasts from continuously stimulated B lymphocytes, which reflects the IgG4-RD inflammation severity, might lead to B lymphocyte lymphoma. A previous study reported a special case [16] of extranodal marginal zone B cell lymphoma in the background of IgG4$\mathrm{RD}$, with malignant tumor cells existing in the presence of non-neoplastic cells. Moreover, in the differentiation process, plasmablasts are possibly transformed into tumorous plasma cells producing numerous monoclonal IgG4 molecules. This supports the comment that once a high level of serum IgG4 was found, monoclonal IgG4 must be excluded. There have been case reports of IgG4 myeloma being mistaken for IgG4-RD [17-19], as well as IgG4 POEMS syndrome [20]. These provide proof that the IgG4 molecule is likely a reactive product of immune dysregulation rather than the primary etiologic mediator in IgG4-RD.

Eosinophilia and tissue eosinophils infiltration are common in IgG4-RD. Eosinophilic angiocentric fibrosis is now part of IgG4-RD, usually affecting orbits and the upper respiratory tract. In the current report, renal eosinophils aggregation was obvious in both patients, even with an absence of eosinophilia as in case\#1. A previous study presented similar findings that eosinophils infiltration was evident in $30.8 \%$ of IgG4-RD patients compared with $9.5 \%$ in non-IgG4 tubulointerstitial nephritis [21]. Regulation of IgG4 production is dependent on Th2 cells and is therefore linked to IgE response and eosinophilia, indicating an underlying inflammation. However, the role of eosinophils in immune-mediated IgG4-RD is not completely understood. In some recently published studies [21-23], the significance of eosinophils to renal fibrosis progression has been focused on. And in animal models, the loss of eosinophil peroxidase could reduce renal fibrosis [23]. All these evidence suggest that eosinophils may represent the inherent characteristic of the immune response in IgG4-RD [24, 25]. Sometimes, IgG4-RD with eosinophilia needs to be differentiated from lymphocyte variant hypereosinophilic syndrome and autoimmune lymphoproliferative syndrome, because both diseases could present eosinophilia and involve the lymph nodes [26, 27].

Disease diagnosis and monitoring based on clinical syndromes and general imaging findings are currently required criteria. Pathological examination of involved tissue remains irreplaceable in the diagnosis of IgG4$\mathrm{RD}$. While in the absence of pathological evidence, it is difficult to accurately distinguish inflammatory from fibrotic activity in human immune-mediated disease in vivo. ${ }^{18} \mathrm{~F}$-FDG-PET/CT has been considered a promising diagnostic tool to aid IgG4-RD diagnosis in recent years. As a whole-body imaging technique, it is reported to detect more lesions in $71.4 \%$ of IgG4-RD patients than the conventional imaging methods, providing a more comprehensive evaluation of disease distribution as an entity [27]. In another reported study, ${ }^{18} \mathrm{~F}$-FDG-PET/ CT had a sensitivity of $85.7 \%$ and specificity of $66.1 \%$ for diagnosing IgG4-RD [28]. The intensity of ${ }^{18}$ F-FDG uptake in IgG4-RD changes along with disease remission and relapse [29]. Although the difference in cutoff SUV values between IgG4-RD and early-stage malignancies is not significant, there are still recognizable characteristics [27], such as the distribution characteristics of hypermetabolic lesions, contributing to a more accurate judgment. Patient \#1 showed prominent IgG4-positive plasma cells infiltration in the bone marrow and arteritis on enhanced-CT, but ${ }^{18} \mathrm{~F}$-FDG-PET/CT did not show high uptake in both sites. It was speculated that ${ }^{18} \mathrm{~F}$-FDG might not be able to visualize chronic fibrotic lesions. At present, more novel PET probes have been exploited to better target fibrotic lesions (i.e., ${ }^{68}$ FAPI) [11] or to detect early changes in lymphoid mass in systemic autoimmunity (i.e., ${ }^{18} \mathrm{~F}$-fluoroarabinofuranosyl cytosine) [30]. This would allow evidence for a more accurate evaluation of immunosuppressive therapy.

Steroids are still the mainstay for IgG4-RD therapy. However, its long-term use is not recommended. B cells depletion strategy is superior to steroids, especially for refractory and recurrent cases. Rituximab has shown a response rate of $97 \%$ in one prospective trial [31] and a lower relapse rate [32]. In case\#1, steroids helped to reach partial remission of renal injury and systemic inflammation. His kidney function finally remained at chronic kidney disease stage 4 . Oppositely, case \#2 was young and diagnosed with early onset of disease, plasma exchange combined with steroids plus Rituximab led to complete remission.

\section{Conclusion}

These two cases illustrate the rare bone marrow involvement in active IgG4-RD accompanied by other hematologic syndromes. The significance of disease pathogenesis is worthy of further study.

\section{Acknowledgements}

None.

\section{Authors' contributions}

SYL contributed to patient management, diagnosis, and manuscript drafting. $\mathrm{HW}$ contributed to patient pathological diagnosis and manuscript drafting; TS contributed to clinical data collection, analysis, interpretation, and intellectual content of critical importance to the work described. All authors had the opportunity to revise the manuscript. We gratefully thank LK and KW for investigating the 18F-FDG-PET/CT and enhanced-CT figures. All authors thank the patients and their families for their support. All authors read and approved the final manuscript. 


\section{Funding}

This study was supported by grants from the National Science and Technology Major Projects for major new drugs innovation and development (2017ZX09304028). The funding supported the long-term follow-up of these patients. The funding body had no role in study design, data collection and analysis, decision to publish, or manuscript preparation.

\section{Availability of data and materials}

The patients were regularly followed up and the clinical data are traceable. The datasets used and analyzed during the current study are available from the corresponding author on reasonable request.

\section{Declarations}

\section{Ethics approval and consent to participate}

Not applicable.

\section{Consent for publication}

Patient consent was obtained for publication.

\section{Competing interests}

The authors declare they have no competing interests.

\section{Author details}

${ }^{1}$ Renal Division, Department of Medicine, Peking University First Hospital, Beijing, China. ${ }^{2}$ Institute of Nephrology, Peking University, Beijing, China. ${ }^{3}$ Renal Division, Department of Medicine, Wangjing Hospital, China Academy of Chinese Medical Sciences, Beijing, China. ${ }^{4}$ Laboratory of Electron Microscopy, Peking University First Hospital, Beijing, China.

Received: 6 November 2021 Accepted: 13 January 2022

Published online: 02 February 2022

\section{References}

1. Kamisawa T, Zen Y, Pillai S, Stone HJ. IgG4-related disease. Lancet. 2015;385(9976):1460-71.

2. Blockmans D. IgG4-related disease. Acta Clin Belg. 2018;73(1):11-5.

3. Zhao EJ, Cheng CV, Mattman A, Chen LYC. Polyclonal hypergammaglobulinaemia: assessment, clinical interpretation, and management. Lancet Haematol. 2021:8(5):e365-75.

4. Harkness T, Fu X, Zhang Y, Choi HK, Stone JH, Blumenthal KJ, et al. Immunoglobulin $\mathrm{G}$ and immunoglobulin $\mathrm{G}$ subclass concentrations differ according to sex and race. Ann Allergy Asthma Immunol. 2020:125(2):190-5.

5. Qi R, Chen LY, Park S, Irvine R, Seidan MA, Kelsall JT, et al. Utility of serum lgG4 levels in a multiethnic population. Am J Med Sci. 2018:355(1):61-6.

6. Chen LYC, Mattman A, Seidman MA, Carruthes MN. IgG4-related disease: what a hematologist needs to know. Haematologica. 2019;104(3):444-55.

7. Ichiki A, Hashimoto N, Ueda T, Hiraiwa S, Tajiri T, Nakamura N, et al. IgG4-related disease with bone marrow involvement. Intern Med. 2016:55(16):2295-9.

8. Mabood Khalil MA, Rajput AS, Ghani R, Ullah SMR, Thet MK, Daiwajna $R G$, et al. Isolated renal involvement by IG4-related disorder mimicking multiple myeloma, a diagnosis not to miss. Saudi J Kidney Dis Transpl. 2021:32(1):249-54.

9. Kamisawa T, Funata N, Hayashi Y, Eishi Y, Koike M, Tsuruta K, et al. A new clinicopathological entity of IgG4-related autoimmune disease. J Gastroenterol. 2003;38(10):982-4.

10. van den Elshout-den UD, Spoto CPE, de Boer M, Leiner T, Leavis HL, Leguit RJ. First report of IgG4 related disease primary presenting as vertebral bone marrow lesions. Front Immunol. 2019;10:1910.

11. Schmidkonz C, Rauber S, Atzinger A, Agarwal R, Gota TI, Soare A, et al. Disentangling inflammatory from fibrotic disease activity by fibroblast activation protein imaging. Ann Rheum Dis. 2020;79(11):1485-91.

12. Kim HJ, You E, Hong S, Park CJ. A Case of IgG4-related Disease with bone marrow involvement: bone marrow findings and flow cytometric immunophenotyping of plasma cells. Ann Lab Med. 2021;41(2):243-6.
13. Sato Y, Inoue D, Asano N, Takata K, Asaoku H, Maeda Y, et al. Association between IgG4-related disease and progressively transformed germinal centers of lymph nodes. Mod Pathol. 2012;25(7):956-67.

14. Wang H, Su T, Li DY, et al. Clinical significance and pathological features of ectopic lymphoid-like structures in lgG4-related tubulointerstitial nephritis. Chin J Nephrol. 2019;35(9):641-7.

15. Wallace ZS, Mattoo H, Carruthers M, Mahajan VS, Torre ED, Lee $H_{\text {, et al }}$ Plasmablasts as a biomarker for lgG4-related disease, independent of serum lgG4 concentrations. Ann Rheum Dis. 2015;74(1):190-5.

16. Harada K, Otsuka F. Cardiac mucosa-associated lymphoid tissue lymphoma involved in IgG4-related disease. Eur Heart J. 2019;41(15):1519.

17. Gauiran DTV, Marcon KM, DeMarco ML, Fung AWS, van der Gugten G, Mattman A, et al. IgG4 plasma cell myeloma without clinical evidence of lgG4-related disease: a report of two cases. Hematology. 2020;25(1):335-40.

18. Ito A, Yamauchi T, Nakano A, Fujino M, Ito M. IgG4 plasma cell myeloma: clinicopathological characteristics and diagnosis. Pathol Int. 2020;70(8):551-6.

19. Geyer JT, Niesvizky R, Jayabalan DS, Mathew S, Subramaniyam S, Geyer Al, et al. IgG4 plasma cell myeloma: new insights into the pathogenesis of IgG4-related disease. Mod Pathol. 2014;27(3):375-81.

20. Zheng M, Zhou P, Zheng K, Meng L, Liu X, Chu M, et al. A special subtype of POEMS syndrome: IgG4 subtype. Am J Transl Res. 2016;8(2):588-96.

21. Yoshita K, Kawano M, Mizushima I, Hara S, Ito Y, Imai N, et al. Lightmicroscopic characteristics of IgG4-related tubulointerstitial nephritis: distinction from non-lgG4-related tubulointerstitial nephritis. Nephrol Dial Transplant. 2012;27(7):2755-61.

22. Tariq A, Okamato K, Tariq A, Rosengerg AZ, Soliman KM, Ploth DW, et al. Eosinophilia and risk of incident end stage kidney disease. BMC Nephrol. 2020;21(1):14

23. Colon S, Luan HY, Liu Y, Meyer C, Gewin L, Bhave G. Peroxidasin and eosinophil peroxidase, but not myeloperoxidase, contribute to renal fibrosis in the murine unilateral ureteral obstruction model. Am J Physiol Renal Physiol. 2019;316(2):F360-71.

24. Della Torre E, Mattoo H, Mahajan VS, Carruthers M, Pillai S, Stone JH. Prevalence of atopy, eosinophilia, and IgE elevation in IgG4-related disease. Allergy. 2014;69(2):269-72.

25. Saeki T, Kobayashi D, Ito T, Tamura M, Yoshikawa S, Yamazaki H. Comparison of clinical and laboratory features of patients with and without allergic conditions in IgG4-related disease: a single-center experience in Japan. Mod Rheumatol. 2018;28(5):845-8.

26. Carruthers MN, Park S, Slack GW, Dalal BI, Skinnider BF, Schaeffer D, et al. IgG4-related disease and lymphocyte-variant hypereosinophilic syndrome: a comparative case series. Eur J Haematol. 2017:98(4):378-87.

27. Zhang J, Chen H, Ma Y, Xiao Y, Niu N, Lin W, et al. Characterizing IgG4related disease with ${ }^{18} \mathrm{~F}-\mathrm{FDG}$ PET/CT: a prospective cohort study. Eur J Nucl Med Mol Imaging. 2014;41(8):1624-34.

28. Lee J, Hyun SH, Kim SE, Kim DK, Lee JK, Moon SH, et al. Utility of FDG PET/ CT for differential diagnosis of patients clinically suspected of IgG4related disease. Clin Nucl Med. 2016;41(5):e237-43.

29. Berti A, Della-Torre E, Gallivanone F, Canevari C, Milani R, Lanzillotta M, et al. Quantitative measurement of 18F-FDG PET/CT uptake reflects the expansion of circulating plasmablasts in lgG4-related disease. Rheumatology (Oxford). 2017;56(12):2084-92.

30. Radu CG, Shu CJ, Nair-Gill E, Shelly SM, Barrio JR, Satyamurthy N, et al. Molecular imaging of lymphoid organs and immune activation by positron emission tomography with a new [18F]-labeled 2'-deoxycytidine analog. Nat Med. 2008;14(7):783-8.

31. Masaki Y, Matsui S, Saeki T, Tsuboi H, Hirata S, Izumi Y, et al. A multi-center phase II prospective clinical trial of glucocorticoid for patients with untreated IgG4-related disease. Mod Rheumatol. 2017;27(5):849-54.

32. Omar $D$, Chen $Y$, Dong L, Cong Y. Glucocorticoids and steroid sparing medications monotherapies or in combination for lgG4-RD: a systematic review and network meta-analysis. Rheumatology (Oxford). 2020;59(4):718-26.

33. Tarte NN, Ravipati CS, Leon de la Rocha JA, Rinker E, Patel NJ. IgG4-related disease with multiorgan involvement: a case-based review. Rheumatol int. 2021:41(6):1169-74.

\section{Publisher's Note}

Springer Nature remains neutral with regard to jurisdictional claims in published maps and institutional affiliations. 